\title{
DO GEOTURISMO À GEOCONSERVAÇÃO: ANÁLISE DA PERCEPÇÃO AMBIENTAL DA COMUNIDADE DO GEOSSÍTIO PONTAL DA SANTA CRUZ- GEOPARK ARARIPE, CE
}

\author{
FROM GEOTOURISM TO GEOCONSERVATION: ANALYSIS OF THE \\ ENVIRONMENTAL PERCEPTION OF THE COMMUNITY OF THE PONTAL OF \\ SANTA CRUZ GEOSITE - GEOPARK ARARIPE, CE
}

\author{
Paloma Duarte Cardoso ${ }^{\mathrm{a}}$ \\ Catarina Pereira Leite ${ }^{b}$ \\ Mileyde Paulino Alves de Limac \\ Marcos Aurélio Figueiredo dos Santos ${ }^{d}$ \\ aUniversidade Regional do Cariri - URCA; Graduanda em Ciências \\ Biológicas.

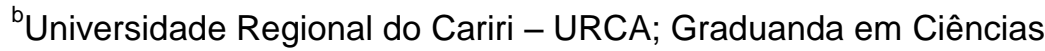 \\ Biológicas, Técnica em Meio Ambiente. \\ 'Universidade Regional do Cariri - URCA; Graduanda em Ciências \\ Biológicas.

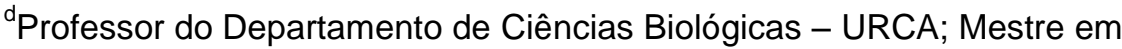 \\ Bioprospecção Molecular.
}

Recebido em: 17/03/2017 I Aceito em: 01/06/2017

ARTIGO

\section{RESUMO}

Através de uma visão holística do meio ambiente e dos recursos naturais, torna-se necessário um planejamento hábil da atividade turística, para que haja o mínimo de impacto possível ao patrimônio natural, pois, o geoturismo é um dos principais instrumentos que impulsionam o desenvolvimento local, sendo, o elo entre o patrimônio geológico e o desenvolvimento sustentável.O objetivo deste estudo foi analisar a percepção ambiental como instrumento da tentativa de se alcançar uma sustentabilidade capaz de prover as necessidades sociais e manter os recursos naturais, dentro das perspectivas e as condições de conservação do Geossítio Pontal da Santa Cruz, interagindo com a comunidade do 
mesmo, buscando informações acerca das questões envolvidas na pesquisa.Para tanto, realizou-se uma revisão bibliográfica, observações e uma pesquisa quali-quantitativa por meio de entrevistas. Os resultados obtidos revelaram a falta de planejamento do turismo na região, não havendo uma gestão voltada especificamente para a atividade na área, decorrente de baixa infraestrutura, havendo a necessidade da inclusão de ações de monitoramento para o geossítio, como também, incluir novas propostas para uma melhor interação da comunidade. Em contra partida, observou-se uma significante percepção ambiental apresentada pelos moradores entrevistados, além de uma vasta influência socioeconômica do geoturismo na região.Concluindo assim, que o Geossítio Pontal da Santa Cruz depende de seus atrativos naturais para um bom desenvolvimento do turismo, sendo o uso consciente do patrimônio natural de grande relevância para a continuação da atividade turística. Considerando também a percepção popular, já que é advinda da pertença, podendo vir a contribuir junto de diagnósticos ambientais científicos.

Palavras-chave: Recursos naturais. Turismo. Desenvolvimento. Sustentabilidade. Conservação.

\section{ABSTRACT}

Through a holistic view of the environment and natural resources, it becomes necessary a skillful planning of the tourist activity, so that there is as little impact as possible on natural heritage, for, thegeotourism is one of the main instruments that drive local development, being the link between geological heritage and sustainable development. The objective of this study was to analyze environmental perception as an instrument of the attempt to achieve a sustainability capable of providing social needs and maintaining natural resources, within the perspectives and conservation conditions of Pontal of Santa Cruz Geosite. Therefore, washeld a bibliography review, comments and a qualitative-quantitative research through interviews. The results showed the lack of tourism planning in the region, and there is no specifically management for the activity in the area, due to low infrastructure. On the other hand, there was a significant environmental perception presented by the residents interviewed, besides a vast socioeconomic influence of geotourism in the region.lt is concluded that the PontalGeositio Santa Cruz depends on its natural attractions for a good development of tourism, and the conscious use of the natural heritage of great relevance for the continuation of the tourist activity. Considering also popular perception, since it is derived from belonging, and can contribute to scientific environmental diagnoses.

Keywords: Natural resources. Tourism. Development. Sustainability. Conservation.

\section{INTRODUÇÃO}

O turismo tem se mostrado uma atividade economicamente viável, sendo realizado em diversas partes do mundo, principalmente naquelas que possuem valorização histórica, cultural e do seu patrimônio natural. Com isto, aos poucos,tem sido observado o surgimento de novos segmentos do turismo focados na conservação dos recursos naturais, sendo um deles, o geoturismo.

Ciência e Sustentabilidade - CeS / Juazeiro do Norte, v. 3, n. 1, p. 124-141, jan/jun 2017 
O geoturismo é um dos principais instrumentos que impulsiona o desenvolvimento local. Moreira (2010) ressalta que o geoturismo pode ser definido como um novo segmento de turismo em áreas naturais, realizado por pessoas que têm o interesse em conhecer mais os aspectos geológicos e geomorfológicos de um determinado local, sendo esta a sua principal motivação na viagem.

Sob esta perspectiva se enquadra o Geossítio Pontal da Santa Cruz, pois se destaca pela riqueza do seu patrimônio geológico, além de sua história cultural. Segundo Azevedo (2007), o geoturismo inclui o patrimônio geológico como seu principal atrativo e através de instrumentos de interpretação ambiental busca sensibilizar o turista.

Geoconservação pode ser entendida com o bom senso aplicado ao uso de recursos naturais. A humanidade depende dos recursos naturais para tudo, não há como levar a vida adiante sem consumir recursos naturais, inclusive os abióticos. Há porém, que fazer uso consciente deles, pois muitos são bens não renováveis e sua conservação implica sempre em investir 0 bastante para se ter retornos recompensáveis (BRILHA, 2005).

Existindo uma relação favorável entre o geoturismo e a conservação, segundo Candeiro et al., (2012) a conservação dos aspectos geológicos e geomorfológicos tem como aliado o geoturismo, este sendo uma ótima oportunidade de promoção do patrimônio geológico, sensibilizando o público geral para a importância de sua conservação.

A percepção ambiental pode ser definida como sendo uma tomada de consciência das problemáticas ligadas ao ambiente, ou seja, 0 ato de perceber 0 ambiente em que se está inserido, aprendendo a proteger e a cuidar do mesmo (FAGGIONATO, 2005). Além disso, pode ser determinada pelas formas como os indivíduos veem, compreendem e se comunicam com o ambiente, considerando-se as influências ideológicas de cada sociedade.

O estudo da percepção ambiental de uma determinada comunidade é um instrumento de notória importância para abrangênciadas ações e conhecimentos acerca do ambiente em estudo, desenvolvendo deste modo, uma postura ética e a sensibilização perante a problemática em estudo. Assim, o artigo possui como objetivo principal analisar a percepção ambiental da comunidade do Geossítio Pontal da Santa Cruz, identificando algumas estratégias de maior promoção do geoturismo 
e da geoconservação na área, contribuindo desta maneira, para utilização e manejo adequado do geossítio.

\section{SEGMENTOGEOTURISMO}

O segmento geoturismo pode ser visto como uma forma de ligação entre o patrimônio geológico e o desenvolvimento sustentável, na medida em que é um tipo de turismo que sustenta e incrementa a identidade de um território considerando a sua geologia, ambiente, cultura, valores estéticos, património e o bem-estar dos residentes (AZEVEDO, 2007).

Segundo Lopes et al., (2011) o geoturismo é uma nova modalidade da atividade turística praticado em áreas urbanas, e principalmente em áreas naturais, tem se apresentado como um segmento promissor da atividade turística com características específicas e essenciais à conservação do patrimônio geológico e ao desenvolvimento econômico local das comunidades envolvidas.

Para que esta atividade seja desenvolvida sustentavelmente é de fundamental importância a participação das comunidades locais e dos turistas na tomada de decisões. Dowling (2008) cita que embora seja muitas vezes difícil e demorado envolver todos os interessados no processo de planejamento, essa participação pode trazer benefícios significativos para a sustentabilidade ambiental, incluindo os aspectos sociais, culturais, econômicos e políticos.

Segundo Azevedo (2007), o geoturismo inclui o patrimônio geológico como seu principal atrativo e através de instrumentos de interpretação ambiental busca sensibilizar o turista, tornando o entendimento dos processos geológicos e geomorfológicos do local acessíveis ao público leigo além de promover e divulgar as ciências da terra. Desse modo, essa prática se apropria da paisagem, promovendo um local em larga escala de visitações.

O geoturismo destaca-se como um importante fator na promoção da conservação do patrimônio natural. Rodrigues (2008) compreende um geoparque como um novo modelo de gestão territorial onde o patrimônio geológico é a base de uma estratégia de desenvolvimento que visa o bem-estar das comunidades locais e manter a integridade física destes ambientes recorrendo para isto a ações integradas a este novo segmento do turismo.

Ciência e Sustentabilidade - CeS / Juazeiro do Norte, v. 3, n. 1, p. 124-141, jan/jun 2017 
Então, percebe-se uma busca de alternativas para práticas sustentáveis, tentando reduzir danos ao meio ambiente e aos seus recursos. Coriolano (2006) afirma que o turismo poderá vir a ser uma atividade de sustentação de um novo modelo de desenvolvimento. Isso devido ao crescente número de pessoas incorporadas às atividades econômicas do tempo livre e do lazer, a necessidade de proteção do patrimônio natural, cultural e as bases educativas necessárias para sustentar e desenvolver o setor, e entre outros fatores.

Muitas comunidades já reconhecem e percebem a importância de conservar os seus patrimônios naturais e culturais, até como atrativos singulares, e trabalham para transmitir isto aos turistas, tornando desta forma a educação ambiental imprescindível a este assunto. Oliveira (2011) explica que comunidades receptoras são sua assinatura, seu verdadeiro atrativo, assim, sua transformação bem como a perda do caráter histórico-cultural promove sua desvalorização e sua desmobilização social.

Segundo Dias (2003), o conceito de desenvolvimento sustentável e do turismo sustentável é intimamente ligado à conservação dos recursos naturais que pode garantir a exploração sem deteriorar os recursos naturais renovando- os, ao mesmo tempo em que vão sendo utilizado satisfazendo a necessidade do momento, sem comprometer a capacidade para atender futuras gerações.

Pode-se dizer que o turismo praticado de acordo com as premissas de desenvolvimento sustentável, contribui para o surgimento de geração e renda por meio de novos negócios, como artesanato local, meios de hospedagem, alimentação, formação e capacitação de mão de obra para o turismo e orienta para o uso dos recursos naturais de forma adequada, visando a conservação e preservação destes recursos (LORENCI, 2013).

Mochiutti (2013) relata que o geoturismo amplia os tipos de aproveitamento dos geossítios e valoriza aqueles que não se pensaria incluir em uma oferta turística tradicional, pois não se baseia somente na apreciação estética ou contemplativa, mas na interpretação daquilo que se vê, na explicação dos materiais, formas e fenômenos, incluindo assim sítios sem um apelo estético, mas com valores principalmente educativos e científicos. Desta forma, o geoturismo vem crescendo a cada ano, apresentando-se como uma nova tendência em termos de turismo em áreas naturais. 


\subsection{Geoconservação}

Diante dos valores da geodiversidade e do patrimônio geológico, e as ameaças que os mesmos estão expostos, faz-se necessário o desenvolvimento da geoconservação que busca a conservação, a manutenção e a gestão sustentável do seu patrimônio natural.

Sharples (2002) define geoconservação como a conservação da geodiversidade por seus valores intrínsecos, ecológicos e (geo) patrimoniais. O autor justifica a importância e necessidade da geoconservação afirmando que a geodiversidade tem muitos valores que são importantes e merecedores de proteção.

Outro conceito sobre geoconservação é apresentado por Pereira (2010) afirmando que a geoconservação tem como alicerces básicos a conservação de elementos da natureza, a promoção da identidade territorial e a utilização racional dos elementos da geodiversidade, através do geoturismo, de forma a perpetuar estes elementos e a sensibilizar os moradores e visitantes para o seu valor científico e educativo.

Para Brilha (2005), a estratégia de conservação deve prosseguir com a avaliação de cada geossítio, quanto a sua vulnerabilidade à degradação ou à perda de fatores naturais e/ou antrópicos. Para o autor, uma das estratégias de geoconservação é a valorização e a divulgação, sendo os geossítios que apresentam baixa vulnerabilidade de degradação os mais indicados para se desenvolver essa estratégia. O conceito de geoconservação é tão recente quanto o de geodiversidade, surgindo com o intuito de aumentar a conservação de todos os elementos, levando desta forma maior atenção a preservação dos recursos naturais não vivos.

Os principais objetivos da geoconservação são denominados os seguintes: conservar e assegurar a manutenção da geodiversidade, proteger e manter a integridade dos locais com relevância em termos de geoconservação, minimizar os impactos adversos dos locais importantes em termos de geoconservação, interpretar a geodiversidade para os visitantes de áreas protegidas e contribuir para manutenção da biodiversidade e dos processos ecológicos dependentes da geodiversidade (SHARPLES, 2002). 
O autor ainda afirma quea geoconservação tem por finalidade reconhecer, conservar e valorizar os constituintes não vivos do meio natural com significado e valor geológico, ou seja, valores de exceção representativos da geodiversidade e, ainda, conservar a capacidade destes fenômenos se modificarem e evoluírem, obedecendo a certos padrões de equilíbrio, inerentes aos sistemas naturais. Estando deste modo, a geoconservação interligada ao geoturismo, pois o mesmo é instrumento favorável para ampliação de determinado local, abrangendo, a comunidade do geossítio em estudo, como ponto chave para desencadear novas possibilidades e métodos construtivos dentro desse segmento.

\section{METODOLOGIA}

\subsection{Caracterização da Área de Estudo}

O Pontal da Santa Cruz está localizado no município de Santana do Cariri$\mathrm{CE}$, nordeste do Brasil, fazendo parte da região Cariri. O município possui $807 \mathrm{~km}^{2} \mathrm{e}$ foi criado em 1885, estando a $510 \mathrm{~km}$ de distância da capital do Estado, Fortaleza, e a $55 \mathrm{~km}$ do município de Crato. Com população de aproximadamente 17,168 habitantes (IBGE, 2015).

O Geossítio encontra-se no reverso da Chapada do Araripe, fazendo parte da formação Exu, onde prevalece os arenitos, os principais responsáveis pelo patrimônio geológico lá existente (GEOPARK ARARIPE, 2012). Apresentando ainda, importante valor funcional, pois contêm alto índice de permeabilidade, armazenando grande quantidade de água das chuvas, fornecendo ao município fontes de água doce e formando verdadeiros aquíferos.

Com Latitude - S 7010‘57\|S e Longitude - O 39¹9‘48, o mirante está próximo ao povoado Pontal da Santa Cruz, a região apresenta clima tropical semiárido com densidade demográfica de 20,07 hab./Km (GEOPARK ARARIPE, 2012). A cobertura vegetal desta área é composta pela Mata Seca que pode vir a ocorrer em pequenas áreas nas encostas da chapada, associada à presença de palmeiras diversas (macaúba, catolé e outras) e de caatinga, ora com predominância arbórea, ora arbustiva. Os solos são do tipo argissolos vermelho-amarelos, latossolos vermelhoamarelos e neossoloslitólicos (IBGE, 2015). 
Subsequente, observa-se a importância da incomensurável diversidade do geossítio Pontal da Santa Cruz, considerando como finalidade a conservação do patrimônio natural, histórico e cultural existentes na Bacia Sedimentar do Araripe, além de representar uma área com grandes perspectivas geoturísticas.

\subsection{Métodos Utilizados para Pesquisa}

A pesquisa iniciou-se com o levantamento bibliográfico, buscando aprimorar os conhecimentos e buscar informações precisas sobre a temática do projeto, além de permitir a expansão sobre o conhecimento de novos métodos e ideias. Foi utilizado o método de pesquisade carácter quali-quantitativo, pois compreendeas ações de descrever, compreender e explicar várias ações decorrentes nas áreas em estudo. Além do mais, foram realizadas observações e anotações da área ao decorrer da pesquisa.

Minayo (2001), define a pesquisa qualitativa como aquela que trabalha com o universo de significados, motivos, aspirações, crenças, valores e atitudes, o que corresponde a um espaço mais profundo das relações, dos processos e dos fenômenos que não podem ser reduzidos à operacionalização de variáveis.

Para coleta de dados, foi desenvolvida uma entrevista estruturada, composta por 10 questões, que foram elaboradas com intuito de fácil entendimento e dentro dos padrões éticos. Os entrevistados assinaram o Termo de Consentimento Livre e Esclarecido conforme a Norma CNS 466/12. Para Günther (2003), esse tipo de pesquisa é o principal instrumento para o levantamento de dados por amostragem.

A entrevista foi composta por diversas variáveis, as variáveis como ressaltam Cervo e Bervian (2002) são aspectos, propriedades ou fatores reais ou potencialmente mensuráveis pelos valores que assumem e discerníveis em um objeto de estudo, são exemplos: a renda, a faixa etária, o grau de escolaridade, o sexo, a profissão e, etc. Assim, foram aplicados 12 questionários na comunidade, de forma aleatória, pois a mesma é de pequena extensão. Coletando dados inicialmente no restaurante do Geossítio e se estendendo até o final da comunidade, mantendo sempre o sigilo de todos os participantes.

O conjunto de informações verbais e de materiais obtidos em campo foram organizados na última parte do trabalho, estruturados a partir dos principais dados

Ciência e Sustentabilidade - CeS / Juazeiro do Norte, v. 3, n. 1, p. 124-141, jan/jun 2017 
adquiridos através do questionário. Realizando uma análise quali-quantitativa, que segundo a Organização Mundial do Turismo (2005), a análise qualitativa é uma forma de abordar a realidade do setor turístico, entretanto, não deve ser considerada uma metodologia alternativa a análise quantitativa, mas sim uma metodologia complementar.

\section{RESULTADOS E DISCUSSÃO}

Os estudos juntamente com as entrevistas conferiram dados de interesse tanto socioeconômicos, quanto geopatrimoniais, desta forma, a análise dos dados foi estabelecida nesta ordem. Para Flick (2009), a análise de conteúdo além de realizar a interpretação após a coleta dos dados, desenvolve-se por meio de técnicas mais ou menos refinadas, é através da análise das entrevistas, que se destacaram as principais reflexões, opiniões e questões levantadas.

Os perfis dos entrevistados contaram com informações como sexo, faixa etária e escolaridade. Portanto, de $100 \%$ dos informantes $80 \%$ correspondem ao sexo masculino e $20 \%$ ao sexo feminino, em relação ao nível de escolaridade foram citados do ensino fundamental incompleto (E. F. I) até ao ensino médio completo ( $E$. M. C).A faixa etária variou relativamente entre adultos a idosos, sendo40 \% com idade entre 20 a 40 anos e 60 \% apresentaram mais de 40 anos, conforme mostra a tabela I.

TABELA I: Perfil dos entrevistados da comunidade.

\section{Perfil dos Entrevistados}

$\begin{array}{llll}\text { Entrevistados } & \underline{\text { Sexo }} & \underline{\text { Faixa etária-anos }} & \text { Escolaridade } \\ \text { Entrevistado } 1 & \text { Masculino } & \text { Mais de } 40 & \text { E F I }\end{array}$




\begin{tabular}{|c|c|c|c|}
\hline Entrevistado 2 & Masculino & Entre 20 a 40 & E M C \\
\hline Entrevistado 3 & Masculino & Mais de 40 & E F I \\
\hline Entrevistado 4 & Masculino & Mais de 40 & E F I \\
\hline Entrevistado 5 & Feminino & Mais de 40 & E F I \\
\hline Entrevistado 6 & Masculino & Mais de 40 & E F I \\
\hline Entrevistado 7 & Masculino & Mais de 40 & E F I \\
\hline Entrevistado 8 & Masculino & Mais de 40 & E F I \\
\hline Entrevistado 9 & Masculino & Entre 20 a 40 & E M C \\
\hline Entrevistado 10 & Feminino & Entre 20 a 40 & E M C \\
\hline Entrevistado 11 & Masculino & Entre 20 a 40 & E F C \\
\hline Entrevistado 12 & Feminino & Entre 20 a 40 & E S I \\
\hline
\end{tabular}

Por meio da análise da faixa etária dos entrevistados, pôde-se observarque ocorreu maior indicação de pessoas mais velhas, sendo uma das possíveis explicações para essa ocorrência, o fato delas possuírem maior tempo de convívio no local, uma vez que podem compreender melhor os fatos levantados e contribuir para o repasse de informações.

No que diz respeito à naturalidade dos entrevistados, 90\% nasceram no local, tendo assim, um vasto conhecimento acerca da região como um todo e especificamente da área em estudo por parte da população. Os outros $10 \%$ vieram de municípios próximos, sendo citados Aurora e Araripe.

Com relação ao conhecimento da história cultural do geossítio, todos os entrevistados relataram informações sobre os acontecimentos históricos no local, levando em conta que por meio desses eventos culturais, houve a implantação da cruz no mirante do Geossítio, o que atualmente conta-se como lenda da região.

Em contra partida, quando interrogados sobre o significado de um Geossítio, $10 \%$ associaram a termos como fósseis e local conservado, 10\% após ouvirem o conceito do termo, afirmaram já ter ouvido falar e os outros $80 \%$ não souberam responder, observando nesse ponto, umbaixo nívelsobre a percepção de alguns conceitos. Visto que, para se ter uma conservação favorável é necessário no mínimo o conhecimento básico dos conceitos ambientais. Do mesmo modo, Amorim Filho 
(2007)aborda em sua pesquisa, que a percepção ambiental constitui a última e decisiva fronteira no processo de uma gestão mais eficiente e harmoniosa do meio.

No que se refere à influência do geossítio para a comunidade, todos os entrevistados mencionaram respostas positivas para o turismo, relatando 0 investimento que os turistas trazem para comunidade, além da geração de empregos através do restaurante. Dentro do contexto de Rodrigues e Jacinto (2009) o turismo só pode ter sustentação com a plena participação das comunidades locais envolvidas desde o planejamento até a gestão.

Entretanto, as observações mostraram um déficit em planos de atividades envolvidas nessa questão, julgando-se desta maneira, necessário a inclusão de iniciativas da administração pública voltadas ao setor, com a necessidade de um maior planejamento para que se venha a acontecer um crescente desenvolvimento do turismo, para Hall (2001) embora o planejamento não possa remediar todos os males ele pode minimizar impactos potencialmente negativos e maximizar retornos econômicos nos destinos.

Sendo viável, nesse sentindo, a criação de uma associação local onde se produza artesanatos com a singularidade da região. Lorenci (2013) inclui ainda, que o turismo contribui para o surgimento de geração de renda por meio de novos negócios, como artesanato local, meios de hospedagem, alimentação, formação e capacitação de mão de obra para o turismo e orienta para o uso dos recursos naturais de forma adequada, visando a conservação desses recursos.Sendo possível que seja um meio favorável para todos que estejam envolvidos, direta ou indiretamente.

Assim, a comunidade ao se envolver com práticas favoráveis com 0 desenvolvimento econômico, traria retornos satisfatórios para a mesma, proporcionando benefícios como transporte, hospedagem, artesanato e outras formas de produção associada ao turismo, todas favoráveis para geração de rendas da própria comunidade.Podendo vir a ocasionarprodutos diferenciais da região, oferecendo algo singular e único aos turistas.

De acordo com o Gráfico I, a maioria dos entrevistados apontam que as visitações turísticas ocorrem frequentemente e sempre ao Geossítio. Subtendendose que a região ao decorrer dos anos está cada vez mais reconhecida, e sendo favorecida principalmente na parte econômica e cultural. 
Paloma Duarte Cardoso; Catarina Pereira Leite; Myleide Paulino Alves de Lima; Marcos Aurélio Figueiredo dos Santos

GRÁFICO I: Citações pelos entrevistados referentes às visitações turísticas ao Geossítio Pontal da Santa Cruz.

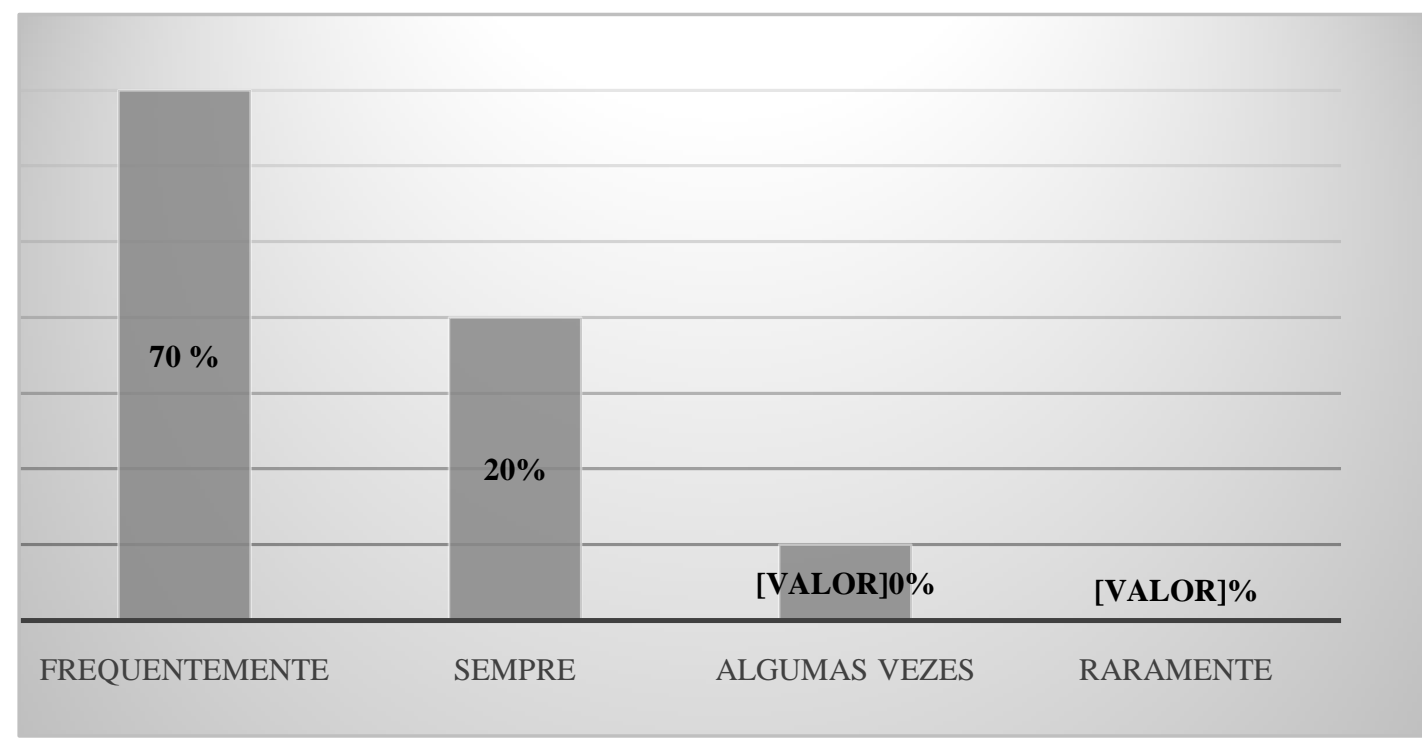

6.

Da mesma forma De La Torre (1997), evidencia a importância sócio cultural e econômica da atividade turística, comprovando que se está bem desenvolvida, é capaz de gerar benefícios para todos os envolvidos, ou seja, podendo ser uma das ferramentas para o desenvolvimento de localidades com potencial para tal.

Em pontos de avanços para melhoria da comunidade e do Geossítio, os entrevistados relataram em maioria, a importância da reconstrução da estrada responsável pelo acesso ao mirante do Geossítio e ao restaurante, citando ainda, aimplantação de uma área de lazer pública. Contudo, faz-se necessário alguns cuidados diante essas restaurações, pois em muitas vezes implicaria grandes mudanças no perfil da paisagem. 
Diante da mesma observação, Barbosa (2006) afirma que enquanto a conservação implica apenas pequenas reparações periódicas, o restauro e a reconstituição envolvem uma intervenção mais profunda, determinada por um estado mais adiantado de degradação. Para muitos, estes restauros são polêmicos e demonstram falta de respeito.

O autor ainda implica que restauro é uma forma de manter vivo o potencial estético do objeto, não descurando o valor documental, mas, de algum modo, ultrapassando-o, pois a representação artística é, neste caso, por si só, legado histórico. Além disso, as paisagens são consideradas excelentes instrumentos de promoção e divulgação da geodiversidade, possibilitando fomentar a sensibilização da sociedade para a geoconservação.

A trilha integrada ao Geossítio é um dos pontos mais atrativos aos visitantes, por proporcionar uma agradável contemplaçãoda beleza natural e a paisagem que lá se encontra, havendo uma preocupação em seu restauro e manutenção, que segundo as informações repassadas pela comunidade, já encontra-se em funcionamento e disponível aos visitantes.

No entanto, não há a implantação de placas no decorrer de todo o Geossítio, fornecendo informações básicas sobre a extensão do percurso, tipo de cobertura da trilha, grau de dificuldade e os tópicos de interpretação a qual o visitante terá acesso. Sendo necessário, a inclusão dessas ações de monitoramento para o geossítio e outros materiais designadamente, visando o registro do número de pessoas que visitam o local.

Além disso, existe a carência de um monitor na condução da trilha, pois o mesmo enriquece as visitações no local.Assim, o investimento em programas de inclusão para os jovens do geossítio, dando enfoque ao público estudantil, poderia instigar a formação de guias turísticos para o auxílio dos visitantes. Moreira (2011) incluindo na mesma visão, diz que o condutor poderá responder perguntas voltadas para questões ambientais, e até desenvolver maior controle no comportamento dos visitantes, inclusive diminuindo seus impactos negativos.

Ao mesmo tempo, há o descarte indevido de materiais dentro da área do Geossítio. Neste caso, recomenda-se que haja investimento derecursos na utilização de sacolas e lixeiras seletivas, preferencialmente de materiais 
oxibiodegradáveis, a fim de contribuir para a manutenção e conservação do ambiente.

Sob esta perspectiva, a comunidade, ao ser questionada sobre a importância da conservação de todos os bens naturais existentes no Geossítio, todos afirmaram que sua conservação é de grande relevância, pois compreendem o seu notório valor e possuem uma certa percepção ambiental nesse sentindo, incluindo todos os aspectos do Geossítio. Dentro do mesmo ponto de vista, Palmer et al.,(1995) ainda afirma que o envolvimento da população local é essencial ao bom sucesso de qualquer projeto de conservação do patrimônio.

Favorecendo deste modo, uma interação positiva entre a comunidade e a ação turística desenvolvida no geossítio.Bertoncell (2004) assegurada mesma forma,que as propostas para o desenvolvimento turístico justificam-se como uma estratégia para maximizar o acesso ao patrimônio e ao mesmo tempo gerar recursos econômicos para sua conservação.

Tendo em vista que a conservação do meio ambiente é um instrumento fundamental no desenvolvimento da atividade turística, percebe-se a importância em ressaltar a educação ambiental como fator indispensável para minimizar os impactos causados pelo turismo ao meio ambiente e a conservação dos recursos naturais. Dias (2003) ainda acrescenta, que o ambiente natural é o principal atrativo da atividade turística, pois a mesma, se apropria dos recursos naturais para desenvolver suas atividades.

Com basenesse contexto, a relação entre percepção e conservação dos recursos naturais é algo imprescindível, haja vista, que o homem elabora em sua visão uma composição entre os fatores pertencentes ao meio ambiente e um determinado grupo social, como forma de criação de um elo, proporcionando uma relação com os valores naturais e culturais.

\section{CONSIDERAÇÕES FINAIS}

Com o presente estudo, foi possível qualificar a área analisada como sendo de grande significância pela diversidade de informações e pelos seus diversos aspectos ambientais, consistindo-se como um geossítiocom importantes valores que o leva a ser prioritário para conservação.

Ciência e Sustentabilidade - CeS / Juazeiro do Norte, v. 3, n. 1, p. 124-141, jan/jun 2017 
A análise permitiu, ainda, inferir que existe uma mínima articulação para o desenvolvimento de uma gestão para o geossítio, a qual sugere-se uma implantação a fim de que haja aproveitamentos e benefícios melhor otimizados e distribuídos. Não somente o valor paleontológico está envolvido, mas também há muitos valores para pesquisas acadêmicas na área, como também, estão incluídos os valores de cunho cultural e geológico. Por outro lado, nesses valores incluem-se as particularidades do local, o que chama a atenção para as relações que a comunidade do entorno trava com o território.

Com a constatação de que há necessidade de incluir novas propostas para uma melhor interação da comunidade, o que aumentaria a popularidade do geossítio e sua atratividade turística, como também, o desenvolvimentode programas para inclusão dos jovens do Geossítio, pois,o investimento na educação ambiental irá favorecer uma maior e permanente conservação do geossítio.

Levando em conta, que a inclusão de ações de monitoramento para o Geossítio se torna indispensáveis, já que, essas medidas ampliariam a infraestrutura do local para melhor recepção dos visitantes, incentivando a população para o uso sustentável do Geossítio, como forma de o valorizar, e principalmente obter-se uma conservação rendável, dando retornos para a comunidade.

O Geossítio Pontal da Santa Cruz depende de seus atrativos naturais para um bom desenvolvimento do turismo, pois, o uso consciente do patrimônio naturalé de grande relevância para a continuação da atividade turística. A comunidade do Geossítio reconhece que é preciso solucionar vários problemas existentes com o propósito de aprimorar a conservação da área, demonstrando de tal modo uma significativa percepção ambiental relacionada aos recursos naturais existentes na área do Geossítio. Assim, recomenda-se a consideração desta percepção popular, já que é advinda da pertença, podendo vir a contribuir junto de diagnósticos ambientais científicos. 
Paloma Duarte Cardoso; Catarina Pereira Leite; Myleide Paulino Alves de Lima; Marcos Aurélio Figueiredo dos Santos

\section{REFERÊNCIAS}

AMORIM FILHO, O.B. Os estudos da percepção como a última fronteira da gestão ambiental. 2007. Disponível em:

<http://ivairr.sites.uol.com.br/percepcaoambi.htm>. Acesso em: 20 fev. 2017.

AZEVEDO, Ú. R. Patrimônio geológico e geoconservação no Quadrilátero Ferrífero, Minas Gerais: potencial para a criação de um geoparque da UNESCO. 2007. Disponível em:

$<$ http://www.degeo.ufop.br/terraCiencias/coloquios/Ilcoloquio/doc_base/Patrimonio Geologico_e_Geoconservacao_no_Quadrilatero_Ferrifero,_Minas_Gerais:_Potencial _para_criacao_de_um_Geoparque_da_Unesco.pdf>Acesso em: 20 fev. 2017.

BRILHA, J. B.R. Patrimônio Geológico e Geoconservação: A conservação da Natureza na sua Vertente Geológica. 2005. Disponível em:

<http://www.dct.uminho.pt/docentes/pdfs/jb_livro.pdf >. Acesso em: 20 fev. 2015.

BARBOSA, M. L. Património é parte do equilíbrio ambiental. Centros históricos. 2006. Disponível em:

<http://www.tintafresca.net/news/newsdetail.aspx?news=ddd9e367-f775- 40a0-98b778a9a7378a6c\&edition=6>. Acesso em: 27 mai. 2016.

CANDEIRO, A. et al. Potencialidades de geoturismo na região do triângulo mineiro: exemplos de Campina Verde, Prata, Ituiutaba e Indianópolis. Turismo, Espaço e Estratégias de Desenvolvimento local. João Pessoa-PB: Editora Universitária da UFPB. 2012.

CERVO, A.L.; BERVIAN, P. A. Metodologia científica. 5o ed. Sao Paulo: Printice Hall.2002. p. 242.

CORIOLANO, L.N.M.T. Bases Conceituais do Desenvolvimento e do Ecoturismo. Turismo e Ambiente: Temas Emergentes. Campinas, SP: Editora Alínea, 2006.

DOWLING. R. K. The Future of Geotourism. Presented at the 3rd International UNESCO Conference of Geoparks, Osnabrueck, Germany, 2008. p. 22-26.

DE LA TORRE, P. O. El Turismo: fénomeno social. 2. ed. México: Fondo de Cultura.1997. p.160.

DIAS, R. Planejamento do Turismo: política e desenvolvimento do turismo no Brasil. São Paulo: Atlas, 2003. p. 13.

Ciência e Sustentabilidade - CeS / Juazeiro do Norte, v. 3, n. 1, p. 124-141, jan/jun 2017 
FAGGIONATO S. Percepção ambiental. 2005. Disponível em: <http://educar.sc.usp.br.> Acesso em: 18 Mai. 2016.

FLICK, U. Introdução à pesquisa qualitativa. J. E. Costa, Trad. Artmed. $3^{\circ}$ ed. São Paulo. 2009.

GEOPARK ARARIPE. Geopark Araripe: Histórias da Terra, do Meio Ambiente e da Cultura. Secretarias das Cidades. Crato-CE. 2012. p.167.

GÜNTHER, H. Como elaborar um questionário Brasília, DF: UnB, Laboratório de Psicologia Ambiental, 2003.

HALL, Colin Michael. Planejamento Turístico: Politicas, processos e relacionamentos. São Paulo: Contexto, 2001.

IBGE- Instituto Brasileiro de Geografia e Estatística. Cidades. 2015.Disponível em: $<$ http://cidades.ibge.gov.br/xtras/perfil.php?codmun=231210> Acesso em: 20 jun. 2016.

LOPES O. S. L. et al. Geoturismo: Estratégia de Geoconservação e de Desenvolvimento Local. Caderno de Geografia. v.21, n.35, 2011.

LORENCI. T.C. 2013.Geoturismo: uma ferramenta auxiliar na interpretação e preservação do patrimônio geopaleontológico da região central do rio grande do sul. Disponível em $<$ http://geoturismobrasil.com/artigos/Dissertacao\%20carmenterezinhabarcelloslorenc i.pdf>. Acesso em: 20 jan. 2016.

MOCHIUTTI. F.N. O patrimônio geológico no desenvolvimento territorial em tibagi, paraná. 2013. Disponível em:

$<$ https://repositorio.ufsc.br/bitstream/handle/123456789/106816/318635.pdf?sequenc $\mathrm{e}=1$ >. Acesso em: 19 fev. 2016.

MOREIRA, C. J. Geoturismo: uma abordagem histórico-conceitual. Turismo e Paisagens Características. v. 3, n.1, 2010.

MINAYO, M. C. de S. O desafio do conhecimento. 10. ed. São Paulo: HUCITEC, 2007. 
Paloma Duarte Cardoso; Catarina Pereira Leite; Myleide Paulino Alves de Lima; Marcos Aurélio

OLIVEIRA, C. Ecoturismo como prática para o desenvolvimento Socioambiental. Revista Brasileira de Ecoturismo, São Paulo, v. 4, n. 2, p. 184-195, 2011.

ORGANIZACAO MUNDIAL DO TURISMO (OMT). Turismo internacional: Uma perspectiva global. $2^{\mathrm{a}}$ ed. Porto Alegre: Bookman, 2003.

PALMER, J.et al. Planning education to carefor the Earth. IUCN, Gland, Switzerland and Cambridge, UK, p.169. 1995.

PEREIRA, R.G. Geoconservação e desenvolvimento sustentável na Chapada Diamantina (Bahia-Brasil). 317 f.Tese (Doutorado em Geologia) -Universidade do Minho, Braga, Portugal. 2010.

RODRIGUES, J. C. Geoturismo: uma abordagem emergente. In: JORNADAS SOBRE A FUNDAÇÃO SOCIAL MUSEU, XVIII. Portugal. Geoturismo e desenvolvimento local. p. 38-61. 2008.

RODRIGUES, J.; JACINTO, A. Geoturismo \& Desenvolvimento Local. Rio Maior (Portugal): Printmor, 2009.

SHARPLES, C. Conceptsandprinciplesofgeoconservation. 2002. Disponível em: <http://www.dpiw.tas.gov.au/inter.nsf/Attachments/SJON57W3YM/\$FILE/ geoconservation.pdf>. Acesso em: 29 fev. 2016. 